\title{
How much "effort" should be devoted to memory?
}

\author{
DAVID B. MITCHELL \\ Southern Methodist University, Dallas, Texas \\ and \\ R. REED HUNT \\ University of North Carolina, Greensboro, North Carolina
}

\begin{abstract}
We focus on the issue of whether cognitive effort is causally related to memory. We begin with a discussion of the concept of cognitive effort as derived from capacity models of attention. We then suggest that the theoretical analysis of memory may involve concepts from different levels of psychological analysis, and we draw a distinction between concepts that represent boundary conditions and sufficient cause. When applied to memory phenomena, attentional concepts serve only as a boundary -or limiting-function in memory theory. In contrast, concepts that represent memorial processes serve as a sufficient cause function. In some instances, cognitive effort appears to have been used as a sufficient cause concept, resulting in some confusion. A review of the literature reveals a haphazard correlation between indexes of cognitive effort and of memory performance. Alternatively, the application of cognitive effort or capacity to the memory performance of certain populations (clinical, children, and elderly) illustrates a potentially more appropriate use of the concept.
\end{abstract}

Whatever future conclusion we may reach as to this, we cannot deny that an object once attended to will remain in the memory, whilst one inattentively allowed to pass will leave no traces behind. (James, 1890, p. 427)

The concepts of attention and memory have been perennially interwoven in the fabric of cognitive theory. Any adequate theory of intellectual functioning must eventually describe the interaction between these concepts, as well as provide a coherent account of the two concepts separately. Research and theory on these concepts logically precede description of their interaction, but the inextricable intertwining of attention and memory sometimes encourages the transfer of concepts from attention to explanations of memory. Since theories of attention and theories of memory, as separate conceptual systems, are designed to address different questions, borrowing concepts from attention to explain questions about memory can lead to confusion and, occasionally, to illogical propo-

\footnotetext{
This article is based in part on a symposium at the 91st Annual Convention of the American Psychological Association in Anaheim, CA (Hunt, 1983). D. B. Mitchell was supported by a Research Fellowship Leave from Dedman College, Southern Methodist University. R. R. Hunt was supported by funds from the Research Council and an Excellence Fund fellowship from the University of North Carolina, Greensboro. We thank Bruce Britton, Ron Kellogg, Henry Ellis, Paula Hertel, Fergus Craik, Larry Jacoby, Cheryl Logan, Jan Rabinowitz, Peter Graf, Cathy Seta, Jeff Toth, Laureen Martin, Jayne Ann Ausley, Robert Guttentag, Charles Brainerd, Valerie Reyna, Alan Brown, Michael Best, Alice Healy, and especially Fred Morrison for their critiques of the ideas discussed here. Requests for reprints should be sent either to Reed Hunt, Department of Psychology, University of North Carolina at Greensboro, Greensboro, NC 27412, or to David Mitchell, Psychology Department, Dedman College, Southern Methodist University, Dallas, TX 75275 .
}

sitions. It is our position that some conceptual confusion has arisen over the application of the attentional concept of cognitive effort as an explanatory mechanism of memory phenomena.

The goal of a theory of attention, in large part, is to describe the selective and limited character of cognitive functioning. The empirical basis for this work has derived historically from the question, "How many things can be done at one time?" Dependent measures of memory have often been used to answer this empirical question. Memory measures are prevalent in empirical studies of attention because theories of attention typically specify a mechanism for selection, and memory performance can be predicted from the hypothetical operation of this selection mechanism. For example, Broadbent's (1958) model of attention assumed that the processes responsible for long-term memory occurred after attentional filtering. Therefore, memory for an experience was believed to be diagnostic of attentional allocation, and many studies of the early selection model used dependent memory measures. If a particular memorial process could operate only after attentional filtering had occurred, then the failure of the memory process to carry through could be ascribed to attentional filtering. Thus, the memory data provide a basis for inferring the operation of the attentional mechanism. In turn, the attentional concept establishes a boundary condition for the explanation of memory performance through the assumption that attention is necessary for memory.

On the other hand, gradations in memory performance would not be explained by attentional filtering. Rather, degrees of retention are explained by reference to particular memorial processes per se (e.g., rehearsal was an 
important concept during the time of Broadbent's theory). Such processes function in theories of memory as concepts that describe the sufficient (or immediate) cause of memory performance. This distinction between the boundary function of attentional concepts and the sufficient cause function of memory concepts will be central to our discussion of cognitive effort.

As theories of attention have evolved, memory for an event can no longer be used in research on attention to infer the occurrence of psychological processes. Contemporary capacity theory of attention has abandoned the assumption that attention is always necessary for memory, and allows for the theoretical possibility of preattentive or automatic processes that consume little or no attentional capacity. Within this framework, the empirical question of "How many things can be done at once?" translates to "How much attentional capacity is required by the processes necessary for a given task?" That the processes actually occurred is inferred from successful (primary) task performance, and the capacity used by these processes is typically inferred from interference on secondary tasks (see Kahneman, 1973; Kerr, 1973). Memory for an event may be a primary task, in which case memory performance will be correlated with the measure of interference to infer the amount of capacity used by the processes responsible for memory performance.

This line of reasoning is well suited to the questions posed by capacity theories of attention, particularly the issue of the capacity requirements of the theoretical processes necessary for task performance. Given the premises of capacity theory, the data produced under the above rationale would be interpreted in terms of the operation of processes that result in task performance and the relative capacity used by these processes. As with Broadbent's (1958) theory, capacity concepts can serve as boundary concepts in theories of memory, but these concepts are no more appropriate as sufficient cause concepts in memory than was Broadbent's attentional filter. Theory and research on cognitive capacity tell us little about the qualitative nature of the processes that occupy that capacity, and it is the description of these processes that constitutes the sufficient cause concepts in theories of memory.

The problem addressed in this paper arises when the reasoning is rearranged such that the proportion of attentional capacity required by a memory task instead determines the degree of processing, which in turn determines the subsequent level of retention. This reasoning is unwarranted by capacity theories, and we shall argue that it creates some confusion for a theoretical analysis of memory. This confusion may arise because the concept of "cognitive effort" has different meanings.

\section{THE CONCEPT OF COGNITIVE EFFORT}

In capacity models of attention, successful task performance is generally seen as a matter of resource require- ments in relation to resource availability. According to Navon (1984), resources may be defined as "any internal input essential for processing (e.g., locations in storage, communication channels) that is available in quantities that are limited at any point in time"' (p. 217). Cognitive effort is technically defined as the percentage of the available capacity or resources allocated to a given task. Under this paradigm, performance of any task will be influenced by resource requirements of the task only if resource demand exceeds resource supply. That is, cognitive effort is theoretically relevant only when capacity requirements outstrip the available processing capacity. Under these conditions, the theory clearly predicts that the fewer resources required by a task, the greater the probability that sufficient resources will be available. In short, when resources are limited, tasks that require less cognitive effort have a higher probability of success than do those that require more cognitive effort.

What, then, are the predictions for a case in which sufficient resources are available for all required tasks? Under such conditions, all tasks would be performed successfully, and no relationship would exist between cognitive effort and task performance. Thus, a capacity model of attention predicts no direct relationship between cognitive effort and performance (but see Norman \& Bobrow's, 1975, discussion of resource-limited processes).

However, highly practiced tasks may require relatively less effort. Thus, it might appear that there is a negative relationship between effort and performance. But in no way would this imply that less effort causes better performance. Rather, the effort expended reflects an individual's degree of skill or task efficiency. When performance requires no measurable resources, the processing is said to be automatic (e.g., Shiffrin \& Schneider, 1977).

\section{Cognitive Effort and Cognitive Capacity}

As we have seen, the capacity model of cognitive effort presumes that performance will be a function of cognitive effort if, and only if, task requirements exceed available resources. The application of this model to memory implies that cognitive effort is an important theoretical consideration only when insufficient capacity is available to support the processes necessary for the retention of an experience. That is, retention failure may be explained in terms of insufficient cognitive effort only if the resource demands of the necessary processes exceed resource supply.

A close examination of the literature reveals two distinct conceptualizations of the relationship between resources and performance. The clarification of these conceptualizations begins with the distinction between cognitive effort and cognitive capacity. One view is that the same operation(s) may be less efficient in one person than in another. Alternatively, the operations may be equally efficient, but one individual may have fewer cognitive resources (see Case, 1984, pp. 37-39). In the former in- 
stance, processing is limited by effort and in the latter, by capacity. With some exceptions (e.g., Case, 1984; Hirst \& Kalmar, 1987; Kail, 1984), the distinction between effort and capacity remains implicit, but this distinction is central to the proper use of attentional concepts in memory theory.

For a given individual at a given instant, capacity is fixed and absolute. If a task requires processes that require resources that exceed available capacity, performance will fail. Thus, resource availability may be a necessary cause of memory processes and, in this sense, can serve as a boundary concept in theories of memory. This is merely a reaffirmation of the assumption that attention is necessary for memory, and even this weak assumption is controversial (e.g., Cheny, 1985; Hasher \& Zacks, 1979; Navon, 1984; Schneider \& Shiffrin, 1985).

In contrast, cognitive effort, defined as the percentage of available resources allocated to processes required by a task, is relative both to task demands and to available capacity. Perhaps it is this relativity that renders the concept so seductive as a sufficient cause of memory. Cognitive effort, unlike cognitive capacity, can vary with the circumstances, tempting the theorist to assume that variations in effort produce variations in memory. However, such a role is unwarranted by capacity theory. As discussed above, cognitive effort is causally related to memory only if there are insufficient resources to support the required processes, a circumstance which reduces to the case of insufficient capacity.

Cognitive effort and cognitive capacity are difficult to discriminate empirically. Depending upon one's point of view, performance failure may be attributable to demand that exceeds the absolute supply of resources, or to the inadequate allocation of resources. Much research on young adults has relied on the assumption that various memory tasks differ in their processing resource demands, which encourages appeals to cognitive effort. Research on memory and aging often harbors the additional assumption that "older people have a smaller pool of processing resources" (Craik \& McDowd, 1987, p. 478; see also Rabinowitz, Craik, \& Ackerman, 1982; Salthouse, 1988). In theory, the inability to discriminate effort and capacity empirically is of little consequence as long as we recognize that neither is a sufficient cause of memory.

\section{Cognitive Effort as Mental Energy}

Many studies of learning and memory have demonstrated that difficult tasks subsequently produce superior memory. One interpretation of this finding is that difficult tasks require greater cognitive effort than do easy tasks and therefore produce better memory (e.g., O'Brien \& Myers, 1985; Tyler, Hertel, McCallum, \& Ellis, 1979; Walker, Jones, \& Mar, 1983). McDaniel, Einstein, and Lollis (1988) have called this interpretation the "difficulty effect." As straightforward as the premise appears to be, examining its assumptions sheds considerable light on the use of a concept of cognitive effort. For example, the defi- nition of "task difficulty" is a nontrivial question in its own right, an issue to which we shall return. The point is that the difficulty effect seems to encourage a view of cognitive effort as the expenditure of energy. Craik and Byrd (1982), for instance, stated that "mental energy is required for the effective functioning of certain mental operations" (p. 192). The analogy here to physical energy and work renders this concept quite appealing. The concept of cognitive effort as mental energy is enhanced by the realization that biological systems expend energy in their functioning, an insight that was perhaps the greatest breakthrough of 19th-century psychophysics. Fechner (1966) articulated the theory that capacity limitation is due to conservation of energy:

The energy needed by the legs for their jump is taken from the flow of psychophysical processes needed for thinking.... [for] while we can divide disposable kinetic energy at will, we can reach a maximum for any one kind of activity only to the extent that we let other activities rest.... Thus also we see the deep thinker sit as much as possible and we never see someone who is running or lifting at the same time in deep thought. This is a contradiction; it cannot occur. (p. 32)

Nonetheless, the issue remains as to how to combine the energy concept with other concepts in our theories. Presumably, cognitive effort in this context would refer to the actual expenditure of energy and thus could be analogous to kinetic rather than potential energy. The notion then is that particular tasks require a certain amount of energy, and the processes involved in accomplishing these tasks are the work energized by cognitive effort. These processes are responsible for memory, but the idea seems to be that the processes are marshaled by cognitive effort. In brief, tasks require energy, and this energy propels the processes.

The belief that task difficulty is ultimately related to memory through cognitive effort could mean that harder tasks require more mental work, which produces better memory. The analogy to "work" must be the operation of the mental processes. The expenditure of energy is analogous to cognitive effort. The energy is consumed and/or released by the work (processing), and is evident only as the process occurs. Thus, cognitive effort as the expenditure of mental energy occurs as the result of processing. Indeed, an energy interpretation of cognitive effort makes it clear that cognitive effort is the result, not the cause, of processing. Since cognitive effort logically cannot cause processing, the concept certainly cannot be used to serve a sufficient cause function in theories of memory.

In summary, cognitive effort is a concept whose lineage, from either capacity or energy metaphors, prescribes a clear relationship between memory processes and effort. Cognitive effort, as either the allocation of capacity or the expenditure of energy, is the product of processing. As such, the concept of cognitive effort cannot be used as a theoretical description of sufficient causes of memory processes. 


\section{EMPIRICAL STUDIES OF COGNITIVE EFFORT AND MEMORY}

A substantial number of experiments have investigated the empirical relationship between cognitive effort and memory. The studies reviewed in this section are those that attempted to establish a direct relationship between cognitive effort and retention in normal adult subjects. Subsequently, we shall review studies involving children, older adults, and clinically depressed patients. The goal of the review in this section is to determine if an empirical case can be made for the use of cognitive effort as a causal concept in memory.

We use the word memory here to refer to retention measures that require conscious recollection on the part of the subject, such as free recall, cued recall, and recognition. Thus, our review excludes recent research on implicit memory measures (see Richardson-Klavehn \& Bjork, 1988; Schacter, 1987), which are sensitive to prior experience but do not require conscious recollection.

Many studies that have invoked the concept of cognitive effort as an explanation for memory data are not useful for the purposes of this review. In particular, these are studies that included no index of cognitive effort (e.g., Ellis, Thomas, \& Rodriguez, 1984; Jacoby, 1978; Jacoby, Craik, \& Begg, 1979; McFarland, Frey, \& Rhodes, 1980; Rabinowitz, Ackerman, Craik, \& Hinchley, 1982; Zacks, Hasher, Sanft, \& Rose, 1983). In addition, a number of studies have included independent measures of difficulty (processing times) but not of cognitive effort (Cairns, Cowart, \& Jablon, 1981; Einstein, McDaniel, Bowers, \& Stevens, 1984; McDaniel, Einstein, Dunay, \& Cobb, 1986; McDaniel et al., 1988; O'Brien \& Myers, 1985). Given the goal of assessing the relationship between $\operatorname{cog}$ nitive effort and memory, independent indexes of both memory and cognitive effort must be available.

In most of the studies that failed to index cognitive effort, effort is inferred from apparent task difficulty. As previously mentioned, the independent variable of task difficulty converges nicely with the energy connotation of cognitive effort, which leads to the inference that any effect of task difficulty on memory can be attributed to the exertion of cognitive effort. There are two related problems associated with this line of reasoning.

The first is a straightforward problem of circularity. Without an independent index of task difficulty, explanations of the effects of task difficulty upon memory, even when mediated by the concept of cognitive effort, are circular. To say that memory is better for a more difficult task requires that task difficulty be defined independently of memory performance. This raises the second and more complex issue of defining task difficulty.

What measures can be used to define the difficulty of a task? A number of indexes may come to mind; perhaps the most obvious are latency and accuracy. In order to interpret any effect of task difficulty in terms of cognitive effort, however, a correlation must be demonstrated between the index of task difficulty and the index of cog- nitive effort. Although the relationship between task difficulty and the concept of cognitive effort may appear so obvious as to make empirical determination of this correlation needless, we must remember that cognitive effort is defined as the percentage of capacity required to perform a task. With this definition in mind, the processes required for an "easy" task may consume just as much capacity as those required for a "hard" task, and the relationship between task difficulty and cognitive effort becomes a nontrivial problem. Indexes of cognitive effort and task difficulty need not be highly related, as illustrated by findings of an inverse relationship between the two factors (Britton, Holdredge, Westbrook, \& Curry, 1979; Britton, Westbrook, \& Holdredge, 1978). Other studies have failed to find positive relations between task difficulty and memory (Jacoby, 1978; Zacks et al., 1983).

Consider a limiting-case thought experiment. Suppose a subject is given two paragraphs, one written in English and the other in Arabic (presuming the subject is not fluent in Arabic). The subject's task is to read these paragraphs for comprehension in a 5-min period. Any error on the comprehension test results in certain and immediate death. The two paragraphs clearly differ in difficulty, as could be shown on any of several measures. In all probability, however, cognitive effort would not differ (i.e., the percentage of capacity burned up by these death-defying tasks would equal $100 \%$ in both cases).

The point is that cognitive effort cannot be inferred directly from task difficulty unless task difficulty is actually defined by cognitive effort. This is exactly the assumption made in most research on attention. Such an assumption is completely reasonable in interpreting memory data, but it necessitates an independent index of cognitive effort. Otherwise, studies of memory as a function of task difficulty have nothing conclusive to say about cognitive effort and memory.

Serious questions may also be raised about the logic of various indexes of capacity utilization. Kahneman (1973) suggested a range of possibilities and later defended quasi-physiological measures, such as pupil dilation, on the grounds of simplicity (Kahneman, 1983). Most of the relevant research on memory has employed dual-task interference as the measure of cognitive effort, for which the rationale is widely known. Nonetheless, considerable controversy remains about the actual measurement of cognitive effort (e.g., Navon, 1984; Wickens, 1984). This issue, however, is beyond the scope of our purposes.

Concerns about independent indexes of cognitive effort notwithstanding, a number of experiments have provided the requisite information for a fair assessment of the relationship between cognitive effort and memory. We shall be looking for two types of relationships. The first type implies that changes in memory are necessarily accompanied by changes in cognitive effort. Violations of this relationship would be represented by changes in memory unaccompanied by changes in cognitive effort. The second type is a sufficiency relationship in which cognitive 
effort is a sufficient cause of memory. Violation of this relationship would be represented by changes in cognitive effort unaccompanied by changes in memory. Thus, the purpose of this review is to examine studies in which manipulations have produced effects upon the indexes of cognitive effort and of memory, and to determine if differences in cognitive effort are consistently related to differences in memory.

\section{Are Differences in Memory Invariably Accompanied by Differences in Cognitive Effort?}

If memory is necessarily related to cognitive effort, all changes in memory should be associated with corresponding changes in cognitive effort. One strategy to explore this hypothesis is to manipulate variables known to affect memory and examine their effect upon cognitive effort. Since in many cases the effects of these variables already have some consensual interpretation, studies that use this strategy are interesting because they may allow us to determine the cognitive effort requirements of accepted theoretical memory processes.

Consistent with this strategy, Johnston and Uhl (1976) measured the cognitive effort (indexed by reaction time to detect a tone) associated with spaced versus massed repetitions of words. Spacing of repetitions is known to affect memory positively and, indeed, Johnston and Uhl found that greater cognitive effort was expended with spaced than with massed repetitions.

Similar conclusions follow from Griffith's (1976) demonstration that elaborate encoding manipulations interfere more with a secondary task than do less elaborate encodings. Griffith's research was the first in a series of attempts to relate cognitive effort to concepts derived from levels of processing (Craik \& Lockhart, 1972). These experiments provide the information needed to determine if cognitive effort can be conceptualized as necessary for hypothetical memory processes such as depth, elaboration, and congruity.

Eysenck and Eysenck (1979) reported an extensive series of experiments designed to examine the relationship between cognitive effort and the variables presumed to affect depth and elaboration of encoding. Subjects were asked questions about either semantic or structural properties of words, a depth manipulation. The questions referred to either one or two attributes of each word, and the answer could be either yes or no. Both of these manipulations have previously been found to encourage broader or more elaborate encoding (Craik \& Tulving, 1975; Klein \& Saltz, 1976; Shulman, 1974). While answering the questions about the words, subjects were also required to respond to either a visual or an auditory signal, and reaction time to the signal was taken as the measure of cognitive effort. Memory performance revealed typical effects: semantic processing was superior to structural processing; "yes" responses were associated with better memory than were "no" responses; and answering two questions was associated with better memory than was answering one question, but only within semantic processing. Reaction time to the auditory and visual signals was longer during semantic than during structural processing, as was also the case in answering two questions rather than one. These results are consistent with Griffith's (1976) data. However, reaction time was greater for questions that required a "no" response than for those that required a "yes" response. Thus, while Eysenck and Eysenck found some positive correlations between cognitive effort, depth of processing, and memory, their data also revealed an inverse relationship between cognitive effort and memory.

In a widely cited study that can be seen as a continuation of this question, Tyler et al. (1979) varied task difficulty orthogonally to depth of processing. Their nonsemantic task required subjects to solve anagrams that were varied in difficulty by rearranging different numbers of letters from the source word. A sentencecompletion task served as the semantic task, and the difficulty of this task was manipulated by varying the extent to which the sentence frame constrained the subject's choice of an appropriate completion. Both the anagram and sentence-completion tasks were presented as matching tasks; that is, the subject saw either an anagram or a sentence frame in conjunction with a target word. The subject had to decide if the word was the solution to the anagram or if it completed the sentence appropriately. This procedure permitted an analysis of performance on "yes" and "no" responses. Reaction time to a tone presented during the orienting task served as the index of cognitive effort.

Tyler et al. (1979) found that recall for the target words varied predictably with all three manipulations. Better memory was associated with semantic than with nonsemantic tasks, with hard than with easy tasks, and with words that correctly solved the problem ("yes" responses) than with those that did not ("no" responses). Cognitive effort was positively related to task difficulty, as reaction time to the tone was longer in conjunction with hard tasks than with easy tasks. On the other hand, cognitive effort differed neither as a function of the semantic-nonsemantic task manipulation nor as a function of yes-no responses. Both of these variables affected memory without necessitating changes in cognitive effort.

Krinsky and Nelson (1981) replicated the Tyler et al. (1979) study using pupillary dilation as an index of cognitive effort. Their results were similar to those of Tyler et al., including finding memory differences for orienting tasks with no corresponding difference in pupillary dilation. If anything, their nonsemantic task exerted larger effects on pupillary dilation than did their semantic task. Krinsky and Nelson reported no direct statistical comparisons between semantic and nonsemantic orienting tasks because the relative task difficulty between their semantic and nonsemantic tasks was unknown and was potentially confounded with the nature of the tasks. Although this argument certainly has some validity, it relies on a different view of the relationship between the variable of 
task difficulty and the concept of cognitive effort than the view normally adopted in attention research. That is, Krinsky and Nelson argued that comparisons of cognitive effort and memory across semantic and nonsemantic tasks are inappropriate because of the lack of a task difficulty scale. If, however, one assumes that cognitive effort reflects task difficulty, then Krinsky and Nelson's index of cognitive effort clearly indicates that their nonsemantic task was more difficult than their semantic task. Yet their semantic task produced superior memory performance. At any rate, Krinsky and Nelson's data replicate the Tyler et al. findings; orienting tasks produced memory changes with no corresponding effect upon cognitive effort.

A lack of a relationship between cognitive effort and memory was also reported by Britton, Meyer, Simpson, Holdredge, and Curry (1979). They asked subjects to read prose passages that contained a target paragraph. The same paragraph was read in the context of two different passages, so that in one passage the paragraph was of major importance and in the other passage it was of minimal importance. Their subjects' reaction time to an auditory signal while reading, the measure of cognitive effort, did not differ as a function of paragraph importance. Memory for the paragraph, however, was much better when the paragraph was important. Once again, these data reveal an effect upon memory unaccompanied by an effect upon cognitive effort.

In summary, a number of studies have found memory differences unaccompanied by differences in cognitive effort (Britton, Meyer, et al., 1979; Eysenck \& Eysenck, 1979; Krinsky \& Nelson, 1981; Tyler et al., 1979). More specifically, variables known to affect memory, with widely accepted interpretations of their effects, do not consistently influence cognitive effort indexes. Semantic processing sometimes requires more cognitive effort than does nonsemantic processing (Eysenck \& Eysenck, 1979; Griffith, 1976), but sometimes the effort required by the two does not differ (Krinsky \& Nelson, 1981; Tyler et al., 1979). Memory for answers to congruent questions ("yes" responses) is better than memory for answers to incongruent questions ("no" responses), but indexes of cognitive effort sometimes fail to reflect this difference (Eysenck \& Eysenck, 1979; Tyler et al., 1979). Thus, theoretical processes presumed to be directly related to retention appear to have no necessary relationship to cognitive effort.

On the other hand, positive correlations between indexes of cognitive effort and of memory have been reported (Britton, Westbrook, \& Holdredge, 1978; Eysenck \& Eysenck, 1979; Griffith, 1976; Johnston \& Uhl, 1976; Krinsky \& Nelson, 1981; Tyler et al., 1979). These empirical relationships may indicate the sufficiency of cognitive effort for memory. While it is clear that not all effects on memory are accompanied by corresponding effects on cognitive effort, changes in cognitive effort may be sufficient to produce changes in memory.

\section{Are Differences in Cognitive Effort Invariably Accompanied by Differences in Memory?}

A number of studies reviewed above reported positive relationships between cognitive effort and memory. Such data are consistent with the notion that changes in cognitive effort are sufficient to produce changes in memory. We will now turn to the question of whether such a relationship exists. As it turns out, a number of experiments have produced contradictory data; that is, variations in cognitive effort unaccompanied by variations in memory.

Kellogg (1984) reported no correlation between cognitive effort and memory for five-letter, nonword stimuli. Under conditions of intentional learning (i.e., subjects were told of a subsequent memory test), subjects were required to respond to an auditory signal. Even though Kellogg found substantial variations in reaction timesan indication of changes in cognitive effort-the subsequent correlations with memory did not differ from zero.

Further challenges to the sufficiency hypothesis have come from Bruce Britton's research on comprehension and capacity utilization. For example, Britton, Piha, Davis, and Wehausen (1978) used Rothkopf's (1966) adjunctive-question technique to enhance the comprehension of technical passages. One group of subjects was given relevant directive questions prior to reading a passage and other groups were given either irrelevant or no questions prior to reading. The relevant-question group was slower in reacting to a click during reading than were the other groups. Memory for the passage, however, was not affected by the questions.

In another study, Britton, Holdredge, Curry, and Westbrook (1979) asked subjects to read Bransford and Johnson's (1972) paragraphs, which are very difficult to comprehend unless preceded by a thematic title. Subjects who were given the title prior to reading the passage were slower to react to a click during reading than were subjects who were not given the title. However, no difference was found between these two groups on a subsequent memory test. This result is problematic because the experimental group should have remembered more than the control group. The memory measure employed by Britton et al. may have not been optimal; therefore the lack of a relationship between effort and memory is inconclusive in this study.

A similar lack of a relationship between cognitive effort and memory, however, was found by Britton (1980). The primary manipulation in this experiment was whether subjects expected an immediate or a delayed memory test for a written passage. Again, a click-detection secondary task was used to measure cognitive effort during reading. Subjects who expected a delayed memory test were slower to react to clicks than were those who expected an immediate test, but memory performance did not differ as a function of time-of-test expectancy.

Finally, Britton, Glynn, Meyer, and Penland (1982) reported two experiments in which variations in cognitive effort again were not accompanied by differences in 
memory. In one experiment, subjects read passages written in either normal or very simple syntax. Reaction time for click detection was much faster in the simple-syntax subjects, but recall did not differ as a function of syntax. In a second experiment, Britton et al. varied the signaling of the important ideas in the passage. "Signals" are special words that alert readers to important ideas and thereby simplify text. Signaling in this study was associated with faster reaction time in the secondary task during reading, but memory did not vary as a function of signaling. This series of experiments provides clear evidence that differences in cognitive effort are not sufficient to produce differences in memory.

Britton's research has also produced one experiment in which cognitive effort and memory were inversely related (Britton et al., 1982, Experiment 2). In that experiment, the syntactical complexity of written passages was varied orthogonally to the frequency of words contained in the passages. Thus, the apparent difficulty of the passages depended both on syntactical complexity and on the familiarity of the words. Not surprisingly, the easiest passages, those with simple syntax and high-frequency words, produced the least interference with secondary-task performance. Furthermore, those same passages (which required the least cognitive effort for comprehension) were best remembered. This result, along with Eysenck and Eysenck's (1979) finding that positive responses required less effort and were better remembered than negative responses, provides evidence that cognitive effort and memory can be inversely related.

\section{Summary of Empirical Studies}

We have seen that the literature provides ample evidence that changes in cognitive effort are not sufficient to produce changes in memory. Indeed, all possible relationships between cognitive effort and memory have been reported, ranging from positive to none to negative. What are we to make of these inconsistencies? If we return to the distinction between a concept that determines the boundary conditions of processes and a concept that causes the processes, the failure to find a consistent relationship between cognitive effort and memory is perfectly understandable.

The hypothetical processes that theoretically result in memory performance are presumed to require mental resources that are in limited supply. In an experiment that requires a subject to perform a task for which memory will later be tested, the mental processes required for the task are responsible for the indexes of cognitive effort and of memory. If the manipulations are such that the processes required to solve one version of the task demand more resources than are required to solve another version of the task, differences in cognitive effort will result. Whether these differences also result in memory, however, depends upon the nature of the processes required to solve the task. In some cases (e.g., solving anagrams), the processes that require greater resources may also be particularly relevant for retention of the task. In other cases (e.g., reading as a function of syntactical com- plexity), the processes that require fewer resources may be particularly relevant to retention. Very simply, capacity availability and capacity utilization are theoretical issues independent of the processes entailed in retention. Whether a task is successfully accomplished depends in large part upon the availability of sufficient resources to service the processes necessary to complete the task. Whether the same task, or any part of it, is subsequently remembered is determined by the nature of the processes required to accomplish the task. Thus, even though Kolers (1975) found decreased memory performance with greater automaticity (i.e., less cognitive effort) in reading inverted text, he attributed the change in memory to a qualitative difference in processing: "Performance ... was not only more rapid; it was also organized differently" (p. 697).

An important contribution to our understanding of the relationship between task difficulty and memory has been outlined in studies by McDaniel and Einstein (Einstein et al., 1984; McDaniel et al., 1986; McDaniel et al., 1988). First, similar to our views on effort, they concluded that "increases in task difficulty do not invariably produce better recall performance"' (McDaniel et al., 1988, p. 12). Second, they have proposed a material appropriate difficulty framework, in which "the difficulty or effort associated with encoding will benefit memory if and only if the type of processing required by the difficulty manipulation is not sufficiently induced by the stimulus itself' (McDaniel et al., 1986, p. 646). Thus, encoding difficulty or effort should not be a simple main effect across a number of other factors. Empirical support for their position comes from research on memory for text (McDaniel et al., 1986) and for words (McDaniel et al., 1988). Although these studies have not addressed effort demands explicitly, we agree with their position that task difficulty will not produce better memory in general. We also have no argument with the position that difficulty can affect memory in certain situations. But the distinction that we stress is between difficulty and effort. When the difficulty of a task causes appropriate processing (e.g., relational, or item-specific, as they suggest), then difficulty has played an important role, but only because it has induced the functioning of the relevant memory mechanisms. The cognitive effort demanded by such processes may or may not be correlated with memory performance.

Cognitive effort, as the utilization of capacity, is thus not related to memory in any direct, causal sense. The sufficient cause of memory performance is memory processes, and indexes of cognitive effort provide virtually no useful information for theoretical descriptions of these processes. It is in this sense that cognitive effort can play little role in theoretical accounts of memory at the proximate level.

On the other hand, capacity and its utilization are determining conditions for memory in that the potential for processes operating is determined by available capacity. If insufficient capacity is available for the operation of necessary processes, memory will fail. With such a role, 
the concept of cognitive effort obviously is important to the operation of cognitive processes, and may serve an important function as a concept establishing theoretical boundary conditions in memory.

\section{COGNITIVE EFFORT AS A BOUNDARY CONCEPT}

To argue that cognitive effort is not a useful concept to describe sufficient causes in memory is not to deny any theoretical role for capacity and cognitive effort in analyses of memory. One may wish to move to another level of theoretical analysis by asking such questions as "Why did the processes not occur?" or "Why are the processes different among different subject populations?" Under certain circumstances, differences in capacity or cognitive effort requirements may be reasonable responses to these questions. The boundary concept may thus serve to explain some aspect of the operation of hypothetical processes.

The most obvious application of cognitive effort as a boundary concept is to the general case in which retention is relatively poor or fails altogether. Such failure may be due to the absence of certain processes, which in turn is due to the absence of cognitive effort. Consider the following interpretation of relatively poor memory performance in older adults: "their encoding, and perhaps retrieval, processes will be impaired whenever the limit of processing resources is exceeded" (Craik \& Byrd, 1982 , p. 193). The processes required for the task do not function, and thus, memory is poor. The processes do not function because they require more cognitive effort than is available.

At one level, the use of cognitive effort as a boundary concept may appear trivial because it is synonymous with the assertion that we can only remember that to which we attend, but this observation is only trivial because it is familiar. In many cases, for example, to say that memory fails because insufficient attention is devoted to the material is to say something of potential theoretical and practical importance about those cases. Such a use of cognitive effort is most obvious when the concept is applied to different subject populations. We shall illustrate this argument by referring to two such recent applications of cognitive effort.

\section{Cognitive Effort, Memory, and Depressed Mood}

Memory deficits are well documented in clinically depressed patients (Badawi, 1985; Henry, Weingartner, \& Murphy, 1973; Lloyd \& Lishman, 1975; Russell \& Beekhuis, 1976; Weingartner, Cohen, Murphy, Martello, \& Gerdt, 1981) as well as in subjects who have been subjected to artificially induced depressed mood states (Bower, Gilligan, \& Monteiro, 1981; Leight \& Ellis, 1981). Why should depression impair memory? Answers to this question have been offered at the level of theoretical memory processes such as organization (Badawi,
1985) and failure to engage in elaborative processing (Weingartner et al., 1981). But why should these processes be less efficient among depressed individuals than among those who are not depressed? Leight and Ellis (1981) expanded on the notion that depression is characterized by negative thought, and argued plausibly that depression produces interference with memory for external events. This interference is at a general level, however, in that the processes that represent negative thoughts compete for capacity with the processes-perhaps organization or elaboration-required for memory of ongoing events. In short, Leight and Ellis have provided a nice example of the use of cognitive effort as a boundary concept by suggesting that the failure of certain memory processes is due to the lack of capacity. Capacity is consumed by the processes responsible for negative thoughts, which precludes the possibility of sufficient cognitive effort devoted to other incoming information.

Note that proponents of this explanation do not claim that depressed patients remember more poorly because they cannot exert cognitive effort, or that memory is necessarily a continuous function of cognitive effort. The implication of this explanation is of considerable practical importance in understanding memory in depression. For example, memory failure is traceable to attention failure, leaving open the possibility that memory for information for which capacity is available will be quite normal. Indeed, Badawi (1985) has shown that clinically depressed patients recall negatively, but not positively, toned material just as well as do nondepressed subjects. Thus, their memory processes are not qualitatively different from those of normal subjects. The poor memory associated with clinical depression is not the result of an inherent lack of capacity or of the general inability to energize memory processes; rather, under certain conditions, the processes required to remember an event simply do not occur.

The value of theories such as that of Leight and Ellis (1981), which use cognitive effort as a boundary concept, is that the emphasis is placed foremost on memory processes. Failure to remember is due to failure of these processes. In specific situations, one might go on to explain the failure of these processes in terms of cognitive effort, but in no sense would one be tempted to conclude that poor memory in clinically depressed patients is caused by a general lack of cognitive capacity or by a general unwillingness to expend cognitive effort.

\section{Cognitive Effort in the Development and Aging of Memory}

Theoretical application of cognitive effort to the analysis of memory in children and older adults has become increasingly popular. Although conceptually less straightforward than the application to clinical depression, the application of cognitive effort to aging and development exemplifies both the complexities and the far-reaching implications of the use of cognitive effort as a boundary concept. 
Guttentag (1985) has provided a thorough review of the similarities between children and older adults in the performance of certain laboratory tasks. The important similarities for purposes of cognitive effort are: both children and older adults are deficient, relative to young adults, on tasks that require deliberate mnemonic strategies (e.g., Cole, Frankel, \& Sharp, 1971; Hultsch, 1971; Lange, 1978; Ornstein \& Naus, 1978; Perlmutter \& Mitchell, 1982); dual-task performance, one of which is a memory task, suffers disproportionately in children and older adults compared with young adults (e.g., Case, Kurland, \& Goldberg, 1982; Craik \& McDowd, 1987; Guttentag, 1984; Kee \& Davies, 1988; Macht \& Buschke, 1983; Salthouse \& Somberg, 1982); age-related differences both in children and in older adults are attenuated in incidental memory tasks, particularly when depth-ofprocessing orienting tasks are provided (e.g., Erber, Herman, \& Botwinick, 1980; Geis \& Hall, 1976; Ghatala, Carbonari, \& Bobele, 1980; Mitchell \& Perlmutter, 1986; Owings \& Baumeister, 1979); and tasks that are presumed to rely on automatic processes reduce or eliminate agerelated differences (e.g., Burke \& Yee, 1984; Hasher \& Zacks, 1979, 1984; Howard, McAndrews, \& Lasaga, 1981). Thus, tasks that apparently require greater cognitive effort reveal larger age-related differences in memory than do tasks that require less cognitive effort.

These patterns provoked Guttentag (1985) to apply Craik's attention deficit hypothesis (e.g., Craik \& Byrd, 1982) to lifespan changes in memory. Craik's analysis of memory deficits in aging emphasizes a decline in mental resources. This decline is associated with decreasing efficiency of the processes responsible for cognitive tasks. Guttentag has argued that the same analysis can be applied to the other end of the age spectrum; that is, that children either gain greater processing resources or develop more efficient processes (which require fewer resources). The former interpretation, that the size of the resource pool changes, is favored in explanations of aging (Craik \& McDowd, 1987; Salthouse, 1988). The alternative interpretation, that there are changes in the operating efficiency of memory and related processes, is favored in accounts of improvements in childhood (Case, 1984; Kail, 1984). Guttentag's synthesis, as well as the previous analyses of children and older adults, is of interest for our purposes because capacity and cognitive effort can be applied as either boundary or sufficient-cause concepts.

For example, memory performance in both children and older adults has been characterized theoretically by inefficient processing. Progress has been made in identifying the specific theoretical processes that differentiate various age groups. Older adults, for instance, appear less likely to integrate to-be-remembered information in the context in which it appears than do younger adults (Rabinowitz \& Ackerman, 1982). Similar conclusions have been drawn from child research (Ackerman, 1983). Integration is presumed to be a useful process that enhances the distinctiveness of the to-be-remembered information (Craik, 1983). Children are less likely than young adults to engage in organizational processes, particularly as reflected in their deliberate rehearsal of material to be remembered (Lange, 1978; Ornstein \& Corsale, 1979). Smith (1980) has proposed the existence of similar process inefficiencies in older adults.

Note that the explanation of memory performance as inefficient processing, especially when a particular process is identified, constitutes a sufficient explanation of age differences in memory. A particular process functions differently across ages, and this difference produces differences in memory. Note further that this conceptualization focuses upon differences in processes and encourages further exploration for descriptions of these differences. At this level, the conceptual framework directs research to concepts that refer to memory processes.

As we begin to raise questions about why memory processes operate differently across age, the level of analysis may shift to the description of boundary conditions. At this juncture, the important point is to recognize whether the concept, whatever it is, is being used in a sufficient cause or boundary sense. The importance of making this discrimination lies in the realization that subsequent research on characterizing development will proceed as a function of different descriptions. To complicate matters further, we must recognize that the same concept can be used at both levels. A brief look at the application of cognitive effort to age differences in memory is illustrative of the conceptual complexity.

As mentioned above, the rise and fall of memory with age can be described in terms of differential processing efficiency. Three of the four general similarities among the memory of children and of older adults are explained fully as processing inefficiency. That is, if the question is why children and the elderly perform differently on memory tests than do young adults, a sufficient explanation can be found in processing differences. Of course, the notion of "inefficient processing" needs to be fleshed out, but the point is that a sufficient explanation of age differences in the use of deliberate mnemonic strategies, the effects of orienting tasks, and automatic processes can be given in terms of memory processes.

Accounting for the remaining point of similarity-the exaggerated effects of dual-task requirements in children and older adults-probably requires an appeal to additional concepts, in particular, to attentional concepts. But it is here that such concepts, including cognitive effort and/or capacity, can function in a boundary sense vis à vis memory.

The reasoning is as follows. Dual-task deficiencies among children and older adults may be due to inadequate capacity or resources devoted to one or both of the tasks. Measures of cognitive effort typically reveal relatively greater effort devoted to a task by children and older adults even though their memory performance on the task is worse than that of young adults (Craik \& McDowd, 1987; Guttentag, 1984; Kee \& Davies, 1988; Macht \& Buschke, 1983). On the surface, this appears either paradoxical or as a direct contradiction to the effort and memory hypothe- 
sis. However, if resources are considered as setting limits rather than as a proximal cause, the paradox is resolved. That is, even though older adults or children may indeed be allocating a greater proportion of their resources, the demand exceeds the supply.

These data, of course, mean that children and older adults perform more poorly on both the primary and secondary tasks than do young adults. Such a pattern is reasonable if we return to the description of single-task performance as inefficient processing. Inefficient processing not only explains poor memory performance, but it also consumes more capacity than does efficient processing (which, of course, is why it is called inefficient). Inefficient processing would thus produce higher estimates of cognitive effort on a given task than would efficient processing. As mentioned above, processing defines cognitive effort. The resource demands of inefficient processing are such that further processing demands of a dualtask situation are even less likely to be met. If one of the tasks involves memory, the inadequate capacity to carry out the necessary processes is important for understanding memory performance. But-and this is the pointthe theoretical analysis of memory as a function of age would not focus on potential age differences in capacity. Rather, the entire chain of reasoning hinges on age differences in processing efficiency.

This line of reasoning, however, can be easily rearranged so that cognitive effort functions as a sufficient cause concept of memory. Consider the following example: "The decreased availability of attentional resources in older people reduces the amount of spontaneously initiated, deep, elaborate, and inferential processing carried out and ... this reduction in turn is associated with lower levels of retention" (Craik \& Byrd, 1982, p. 205). The most straightforward interpretation of this position is that older people have fewer resources, which reduces the likelihood of processes occurring. Similar opinions have been expressed in the analysis of children's memory (e.g., Guttentag, 1985). Used in this sense, the lack of cognitive capacity is the cause of inefficient processing.

The problem with this reasoning is the confusion in the conceptual relationship between capacity and memory processes. This analysis implies that limited capacity conceptually precedes processing inefficiency, and thus it becomes very easy to view limited capacity as the cause of inefficient processing. Such thinking reverses the theoretical relationship inherent in a capacity model of attention, which specifies that processes occupy capacity.

The importance of adopting the latter perspective lies in the focus it places on the theoretical analysis of memory processes. Alternatively, granting conceptual precedence to cognitive effort over processes directs research efforts and theoretical analysis away from processes and toward capacity and cognitive effort. Previous efforts to apply developmental differences in capacity as a causal factor in children's memory illustrate the problems inherent in this approach (e.g., Chi, 1976).

The cause of inadequate resources poses a more difficult (and currently unresolved) question. Is it the case that, as some investigators have suggested (Craik \& McDowd, 1987; Salthouse, 1988), the pool of resources diminishes with age? Or are the operations of children and older adults less efficient, requiring too many resources even though the size of the resource pool has remained constant? The latter interpretation is supported by child research; developmental changes in operational efficiency are implied, as opposed to changes in cognitive capacity (Case et al., 1982). Recent research with young adults, however, has demonstrated that both resource size and operational efficiency can change as a function of experience (Hirst \& Kalmar, 1987). Yet another perspective from problem-solving research is that inefficient processing in aging is not related to cognitive capacity (Charness, 1987). Indeed, two studies (Duchek, 1984; Hiscock, Kinsbourne, Samuels, \& Krause, 1987) report no age differences in cognitive effort in spite of age differences in memory performance. Regardless of the ultimate outcome in this area, our point is simply that processing resources can have a potential role in accounting for some of the age-related changes in memory only when applied as a boundary concept.

\section{SUMMARY}

Attention and memory have long been intertwined in the conceptual analysis of intellectual functioning. Concepts related to attention, such as capacity and cognitive effort, are extremely useful for complete descriptions of memory performance, but these concepts function at a different level of theoretical analysis than concepts that describe memory processes. Psychological processes provide a sufficient cause description of memory phenomena in that these processes are the direct cause of memory performance. These same processes consume capacity (limited resources) and thus are responsible for indexes of cognitive effort. Therefore, some covariation between cognitive effort and memory performance is to be expected, but as the literature already reveals, the correlation between indexes of cognitive effort and memory is not impressive in the consistency of either its magnitude or direction.

Cognitive effort is not a concept that stands in direct theoretical relation to memory performance. Likewise, neither cognitive effort nor mental energy represent the causes of psychological processes that describe memory directly. Rather, cognitive effort is an important concept in attention which can be brought to bear on memory performance to describe potential and limiting conditions of psychological processes.

Used in this boundary sense, cognitive effort and resource limitation may be useful concepts in application to memory, particularly to differences in the cognitive processes of special populations. Keeping in mind that psychological processes consume the limited capacity and determine the cognitive effort expended, theoretical analysis of memory must neither begin nor end with capacity limitation and cognitive effort. To assert that differences in memory as a function of age, for example, are caused 
by differences in cognitive effort, is to direct research away from a detailed understanding of the process concepts so important to theories of memory. Discussion of capacity differences in relation to memory performance prior to some understanding of the processes is at best premature, and is probably detrimental to the analysis of memory.

\section{REFERENCES}

Ackerman, B. P. (1983). Encoding distinctiveness and the encoding shift penalty in children and adults. Journal of Experimental Child Psychology, 36, 257-283.

BADAWI, I. Y. (1985). Cognitive processes in depression: The effects of content and presentation variables on organization and recall. Unpublished doctoral dissertation, University of North Carolina at Greensboro.

Bower, G. H., Gilligan, S. G., Monteiro, K. P. (1981). Selec tivity of learning caused by affective states. Journal of Experimental Psychology: General, 110, 451-473.

Bransford, J. D., \& Johnson, M. K. (1972). Contextual prerequisites for understanding: Some investigations of comprehension and recall. Joumal of Verbal Leaming \& Verbal Behavior, 11, 717-726.

BritTon, B. K. (1980). Effects of cognitive capacity in reading: Effects of processing information from text for immediate recall and retention. Journal of Reading Behavior, 12, 129-137.

Britton, B. K., Glynn, S. M., Meyer, B. J. F., \& Penland, M. J. (1982). Effects of text structure on use of cognitive capacity during reading. Joumal of Educational Psychology, 74, 51-61.

Britton, B. K., Holdredge, T. S., Curry, C., Westbrook, R. D. (1979). Use of cognitive capacity in reading identical texts with different amounts of discourse level meaning. Joumal of Experimental $P$ sychology: Human Learning \& Memory, 5, 262-270.

Britton, B. K., Holdredge, T. S., Westbrook, R. D. \& Curry, C. (1979). Using cognitive capacity in reading text. Perceptual \& Motor Skills, 48, 395-400.

Britton, B. K., Meyer, B. J., Simpson, R., Holdredge, T. S., \& CURRY, C. (1979). Effects of the organization of text on memory: Tests of two implications of selective attention hypotheses. Journal of Experimental Psychology: Human Leaming \& Memory, 5, 496-506.

Britton, B. K., Piha, A., Davis, J., \& Wehausen, E. (1978). Reading and cognitive capacity usage: Adjunct question effects. Memory \& Cognition, 6, 266-273.

BrITton, B. K., WestrRook, R. D., \& HoldRedge, T. S. (1978). Reading and cognitive capacity usage: Effects of text difficulty. Journal of Experimental Psychology: Human Learning \& Memory, 4, 582-591.

Broadbent, D. E. (1958). Perception and communication. London: Pergamon Press.

Burke, D. M., \&eE, P. L. (1984). Semantic priming during sentence processing by young and older adults. Developmental Psychology, 20, 903-910.

Cairns, H. S., Cowart, W., Jablon, A. D. (1981). Effects of prior context upon the integration of lexical information during sentence processing. Joumal of Verbal Learning \& Verbal Behavior, 20, 454-469.

CASE, R. (1984). The process of stage transition: A neo-Piagetian view. In R. J. Sternberg (Ed.), Mechanisms of cognitive development (pp. 1944). New York: W. H. Freeman.

Case, R., Kurland, M., \& Goldberg, J. (1982). Operational efficiency and the growth of short-term memory span. Journal of Experimental Child Psychology, 33, 386-404.

Charness, N. (1987). Component processes in bridge bidding and novel problem-solving tasks. Canadian Journal of Psychology, 41, 223-243.

Cheny, P. W. (1985). Categorization and response competition: Two nonautomatic factors. Psychological Review, 92, 585-586.

СH, M. T. H. (1976). Short-term memory limitations in children: Capacity or processing deficits? Memory \& Cognition, 4, 559-572.

Cole, M., Frankel, F., \& Sharp, D. (1971). Development of free recall learning in children. Developmental Psychology, 4, 109-123.
Cralk, F, I, M. (1983). On the transfer of information from temporary to permanent memory. Philosophical Transactions of the Royal Society of London, 302, 341-359.

Cralk, F. I. M., Brrd, M. (1982). Aging and cognitive deficits: The role of attentional resources. In F. I. M. Craik \& S. Trehub (Eds.) Aging and cognitive processes (pp. 191-211). New York: Plenum.

Craik, F. I. M., LockharT, R. S. (1972). Levels of processing: A framework for memory research. Journal of Verbal Learning \& Verbal Behavior, 11, 671-684

Craik, F. I. M., McDowd, J. M. (1987). Age differences in recall and recognition. Joumal of Experimental Psychology: Learning. Memory, \& Cognition, 13, 474-479.

Craik, F. I. M., Tulving, E. (1975). Depth of processing and the retention of words in episodic memory. Journal of Experimental Psychology: General, 104, 268-294.

DucheK, J. M. (1984). Encoding and retrieval differences between young and old: The impact of attentional capacity usage. Developmental Psychology, 20, 1173-1180.

Einstein, G. O., McDaniel, M. A., Bowers, C. A., Stevens, D. T (1984). Memory for prose: The influence of relational and propositionspecific processing. Joumal of Experimental Psychology: Leaming. Memory, \& Cognition, 10, 133-143.

Ellis, H. C., Thomas, R. L., Rodriguez, I. A. (1984). Emotional mood states and memory: Elaborative encoding, semantic processing, and cognitive effort. Joumal of Experimental Psychology: Leaming, Memory, \& Cognition, 10, 483-495.

Erber, J. T., Herman, T. G., Botwinick, J. (1980). Age differences in memory as a function of depth of processing. Experimental Aging Research, 6, 341-348.

Eysenck, M. W., Eysenck, M. C. (1979). Processsing depth, elaboration of encoding, memory store, and expended processing capacity. Journal of Experimental Psychology: Human Leaming \& Memory. $5,472-484$.

Fechner, G. (1966). Elements of psychophysics (Vol. 1) (H. E. Adler, Trans.). New York: Holt, Rinehart \& Winston.

GEIS, M. F., HALL, D. M. (1976). Encoding and incidental memory in children. Joumal of Experimental Child Psychology, 22, 58-66.

Ghatala, E. S., Carbonari, J. P., Bobele, L. Z. (1980). Developmental changes in incidental memory as a function of processing level, congruity, and repetition. Journal of Experimental Child Psychology, 29, 74-87.

Griffith, D. (1976). The attentional demands of mnemonic control processes. Memory \& Cognition, 4, 103-108.

GUTTENTAG, R. E. (1984). The mental effort requirement of cumulative rehearsal: A developmental study. Journal of Experimental Child Psychology, 37, 92-106.

GuttentaG, R. E. (1985). Memory and aging: Implications for theories of memory development during childhood. Developmental Review, 5, 56-82.

HaSher, L., ZaCKs, R. T. (1979). Automatic and effortful processes in memory. Journal of Experimental Psychology: General, 108, 356-388.

Hasher, L., \& Zacks, R. T. (1984). Automatic processing of fundamental information: The case of frequency of occurrence. American Psychologist, 39, 1372-1388.

Henry, G. M., Weingartner, H., \& Murphy, D. L. (1973). Influence of affective states and psychoactive drugs on verbal learning and memory. American Journal of Psychiatry, 130, 966-971.

HIRST, W., \& KALMAR, D. (1987). Characterizing attentional resources. Journal of Experimental Psychology: General, 116, 68-81.

Hiscock, M., Kinsbourne, M., Samuels, M., Krause, A. E. (1987). Dual task performance in children: Generalized and lateralized effects of memory encoding upon the rate and variability of concurrent finger tapping. Brain \& Cognition, 6, 24-40.

Howard, D. V., McAndrews, M. P., Lasaga, M. I. (1981). Semantic priming of lexical decisions in young and old adults. Journal of Gerontology, 36, 707-714.

Hultsch, D. F. (1971). Organization and memory in adulthood. Human Development, 14, 16-29.

HuNT, R. R. (1983, August). What will more "effort" tell us about memory? In D. B. Mitchell (Chair), Limited capacity, automaticity, 
and effort: Memorable concepts? Symposium conducted at the $91 \mathrm{st}$ Annual Convention of the American Psychological Association, Anaheim, CA.

JACOBY, L. L. (1978). On interpreting the effects of repetition: Solving a problem versus remembering a solution. Journal of Verbal Leaming \& Verbal Behavior, 17, 649-667.

JACOBY, L. L., CRAIK, F. I. M., \& BEGG, I. (1979). Effects of decision difficulty on recognition and recall. Joumal of Verbal Learning \& Verbal Behavior, 18, 585-600.

JAMES, W. (1890). The principles of psychology (Vol. 1). New York: Holt.

Johnston, W. A., UhL, C. N. (1976). The contributions of encoding effort and variability to the spacing effect on free recall. Journal of Experimental Psychology: Human Leaming \& Memory, 2, 153-160.

Kahneman, D. (1973). Attention and effort. Englewood Cliffs, NJ: Prentice-Hall.

Kahneman, D. (1983, August). Current assessment of limited capacity concepts and their applications. In D. B. Mitchell (Chair), Limited capacity, automaticity, and effort: Memorable concepts? Symposium conducted at the 91 st annual convention of the American Psychological Association, Anaheim, CA.

KAIL, R. (1984). The development of memory in children (2nd ed.). New York: W. H. Freeman.

KfE, D. W., DAvies, L. (1988). Mental effort and elaboration: A developmental analysis. Contemporary Educational Psychology, 13, 221-228.

Kellogg, R. T. (1984). Cognitive effort and memory revisited. Psychological Reports, 54, 840.

KERR, B. (1973). Processing demands during mental operations. Memory \& Cognition, 1, 401-412.

KLEIN, K., \& SALTZ, E. (1976). Specifying the mechanisms in a levelsof-processing approach to memory. Journal of Experimental Psychology: Human Learning \& Memory, 2, 671-679.

Kolers, P. A. (1975). Memorial consequences of automatized encoding. Joumal of Experimental Psychology: Human Leaming \& Memory, 1, 689-701.

Krinsky, R., \&elson, T. O. (1981). Task difficulty and pupillary dilation during incidental learning. Journal of Experimental Psychology: Human Learning \& Memory, 7, 293-298.

LANGE, G. (1978). Organization-related processes in children's recall. In P. A. Ornstein (Ed.), Memory development in children. Hillsdale, NJ: Erlbaum.

LEIGHT, K. A., ELLIS, H. C. (1981). Emotional mood states, strategies, and state dependency in memory. Journal of Verbal Learning \& Verbal Behavior, 20, 251-266.

Lloyd, C. G., Lishman, W. A. (1975). Effects of depression on the speed of recall of pleasant and unpleasant experiences. Psychological Medicine, 5, 173-180.

MaChT, M. L., \& BuschKe, H. (1983). Age differences in cognitive effort in recall. Joumal of Gerontology, 38, 695-700.

McDaniel, M. A., Einstein, G. O., Dunay, P. K., \& Cobb, R. E. (1986). Encoding difficulty and memory: Toward a unifying theory. Journal of Memory \& Language, 25, 645-656.

McDaniel, M. A., Einstein, G. O., Lolus, T. (1988). Qualitative and quantitative considerations in encoding difficulty effects. Memory \& Cognition, 16, 8-14.

MCFarland, C. E., Frey, T. J., Rhodes, D. D. (1980). Retrieval of internally versus externally generated words in episodic memory. Journal of Verbal Learning \& Verbal Behavior, 19, 210-225.

Mrtchell, D. B., \& Perlmutter, M. (1986). Semantic activation and episodic memory: Age similarities and differences. Developmental Psychology, 22, 86-94.

Navon, D. (1984). Resources-a theoretical soupstone? Psychological Review, 91, 216-234.

Norman, D. A., BOBRow, D. J. (1975). On data-limited and resourcelimited processes. Cognitive Psychology, 7, 44-64.

O'Brien, E. J., \& MYers, J. L. (1985). When comprehension difficulty improves memory for text. Journal of Experimental Psychology: Learning, Memory, \& Cognition, 11, 12-21.
Ornstein, P. A., Corsale, K. (1979). Process and structure in children's memory. In G. Whitehurst (Ed.), The functions of language and cognition. New York: Academic Press.

Ornstein, P. A., \& NAUS, M. J. (1978). Rehearsal processes in children's memory. In P. A. Ornstein (Ed.), Memory development in children. Hillsdale, NJ: Erlbaum.

OWINGs, R. A., BAUMeister, A. A. (1979). Levels of processing, encoding strategies, and memory development. Joumal of Experimental Child Psychology, 28, 100-118.

Perlmutter, M., Mitchell, D. B. (1982). The appearance and disappearance of age differences in adult memory. In F. I. M. Craik \& S. Trehub (Eds.), Aging and cognitive processes (pp. 127-144). New York: Plenum.

Rabinowitz, J. C., \& Ackerman, B. P. (1982). General encoding of episodic events by elderly adults. In F. I. M. Craik \& S. Trehub (Eds.), Aging and cognitive processes (pp. 145-154). New York: Plenum.

Rabinowitz, J. C., Ackerman, B. P., Craik, F. I. M., HinchLEY, J. L. (1982). Aging and metamemory: The roles of relatedness and imagery. Joumal of Gerontology, 37, 688-695.

Rabinowitz, J. C., Craik, F. I. M., \& Ackerman, B. P. (1982). A processing resource account of age differences in recall. Canadian Joumal of Psychology, 36, 325-344.

Richardson-KLAVEhN, A., \& Bjork, R. A. (1988). Measures of memory. Annual Review of Psychology, 39, 475-543.

RoTHKOPF, E. Z. (1966). Learning of written instructive material: An exploration of the control of inspection behavior by test-like events. American Educational Research Journal, 3, 241-249.

Russell, P. N., \& BeEkHUIs, M. E. (1976). Organization in memory: A comparison of psychotics and normals. Journal of Abnormal Psychology, 85, 241-249.

Salthouse, T. A. (1988). Resource-reduction interpretations of cognitive aging. Developmental Review, 8, 238-272.

Salthouse, T. A., \& Somberg, B. L. (1982). Skilled performance: Adult age and experience on elementary processes. Journal of Experimental Psychology: General, 111, 176-207.

SCHACTER, D. L. (1987). Implict memory: History and current status. Journal of Experimental Psychology: Learning, Memory, \& Cognition, 13, 501-518.

SCHNEIDER, W., Shiffrin, R. M. (1985). Categorization (restructuring) and automatization: Two separate factors. Psychological Review, 92, 424-428.

Shiffrin, R. M., \& Schneider, W. (1977). Controlled and automatic human information processing: Perceptual learning, automatic attending, and a general theory. Psychological Review, 84, 127-190.

ShuLMan, A. I. (1974). Memory for words recently classified. Memory \& Cognition, 2, 47-52.

SMrTH, A. D. (1980). Age differences in encoding, storage, and retrieval. In L. W. Poon, J. L. Fozard, L. S. Cermak, D. Arenberg, \& L. W. Thompson (Eds.), New directions in memory and aging (pp. 23-45). Hillsdale, NJ: Erlbaum.

Tyler, S. W., Hertel, P. T., McCallum, M. C., \& Ellis, H. C (1979). Cognitive effort and memory. Journal of Experimental Psychology: Human Learning \& Memory, 5, 607-617.

Walker, N., Jones, J. P., \& Mar, H. H. (1983). Encoding processes and the recall of text. Memory \& Cognition, 11, 275-282.

Weingartner, H., Cohen, R. M., Murphy, D. L., Martello, J., \& GeRDT, C. (1981). Cognitive processes in depression. Archives of General Psychiatry, 33, 42-47.

WiCKens, C. D. (1984). Processing resources in attention. In R. Parasuraman \& D. R. Davies (Eds.), Varieties of attention. Orlando, FL: Academic Press.

Zacks, R. T., Hasher, L., SANFT, H., \& Rose, K. C. (1983). Encoding effort and recall: A cautionary note. Journal of Experimental Psychology: Learning, Memory, \& Cognition, 9, 747-756.

(Manuscript received June 22, 1987; revision accepted for publication October 17,1988 .) 